\title{
Vaccine potential of LenA and LcpA proteins of Leptospira interrogans in combination with Escherichia coli heat-labile enterotoxin, B subunit (LTB)
}

\author{
Mehran Ghazali-Bina ${ }^{1}$, Mohammad Reza Pourmand ${ }^{1}$, Abbas Mirshafiey ${ }^{2}$, Ronak Bakhtiari', \\ Azad Khaledi ${ }^{3,4}$, Hamid Kazemian', Davoud Afshar ${ }^{5}$, Muhammad Ibrahim Getso ${ }^{6}$, \\ Saeid Eshraghi ${ }^{{ }^{*}}$
}

${ }^{1}$ Department of Microbiology, School of Public Health, Tehran University of Medical Sciences, Tehran, Iran ${ }^{2}$ Department of Immunology, School of Public Health, Tehran University of Medical Sciences, Tehran, Iran ${ }^{3}$ Infectious Diseases Research Center, Kashan University of Medical Sciences, Kashan, Iran

${ }^{4}$ Department of Microbiology and Immunology, Faculty of Medicine, Kashan University of Medical Sciences, Kashan, Iran

${ }^{5}$ Department of Microbiology and Virology, School of Medicine, Zanjan University of Medical Sciences, Zanjan, Iran

${ }^{6}$ Department of Medical Mycology, School of Public Health, Tehran University of Medical Sciences, Intenational College, Tehran, Iran

Received: November 2018, Accepted: January 2019

\begin{abstract}
Background and Objectives: Leptospirosis is a zooanthroponosis caused by the genus of Leptospira. It is an emerging public health problem due to its increasing incidence. The achievement to a vaccine that prevent from entrance of Leptospira interrogans to the deeper tissues of the host is needed. This study aimed to investigate the immunogenicity of LcpA (rLcpA) and LenA (rLenA) recombinant proteins in combination with LTB (rLTB) recombinant protein as an adjuvant against leptospiral infection in hamsters.

Materials and Methods: The genes encoding these proteins were cloned into pGH cloning vector and then $\operatorname{len} A, l c p A$ and $l t b$ genes subcloned into $\mathrm{pET}-15 \mathrm{~b}$ and $\mathrm{pET}-28 \mathrm{a}$ expression vectors, respectively. The hamsters were immunized with the purified recombinant proteins and challenged with Leptospira interrogans for evaluation of their survival. The antibody responses to the recombinant proteins were determined by ELISA. Then, data entered into SPSS software. Statistical Kruskal-Wallis test was used to compare the significant differences among different groups. The groups with significant differences were further analyzed by post hoc tests. The $p$ value $<0.05$ statistically was considered significant.

Results: Immunized hamsters with rLenA-plus-rLTB, rLcpA-plus-rLTB and rLenA-plus-rLcpA-plus-rLTB proteins showed $60 \%, 74 \%$, and $80 \%$ survival rates, respectively. A significant amount of interleukin-17 (IL-17), interleukin-4 (IL-4) and gamma interferon (IFN $\gamma$ ) cytokines were produced in immunized hamsters.

Conclusion: Based on our findings, rLcpA and rLenA proteins in combination with rLTB can protect the hamsters against L. interrogans and effectively induce a protective antibody response. Thus, these proteins can be used as an additional prophylactic tool against leptospira.
\end{abstract}

Keywords: Immunogenicity; Leptospira interrogans; Recombinant proteins; Vaccine

"Corresponding author: Saeid Eshraghi, Ph.D, Department of Microbiology, School of Public Health, Tehran University of Medical Sciences, Tehran, Iran.
Tel: +98 9126363134

Fax: +982188954913

Email: eshraghs@tums.ac.ir 


\section{INTRODUCTION}

Leptospirosis is an emerging global zoonotic disease, caused by pathogenic bacteria belonging to the genus Leptospira (1). Large outbreaks of leptospirosis have recently occurred in many countries, especially in South-East Asian region and in South America (2). Pathogenic Leptospira species are invasive and have the ability to colonize and invade the renal tubules of incidental hosts like rodents, dogs, cats, cattle, pigs, and horses, presenting with variable clinical symptoms (3). Clinical manifestations are ranging from a mild febrile illness to severe disease that can include fever, headache, vomiting, diarrhea, anorexia, muscle pain and constipation $(4,5)$. The adhesion of pathogenic Leptospira to the mucous membrane of the hosts was considered to be essential during the early stage of the infection (6).

There is an urgent need to explore alternative strategies against leptospiral infections, including vaccine production. The currently available leptospiral vaccines are based on inactivated Leptospiral whole cell or membrane preparations of the pathogenic and have low efficacy. However, these vaccines stimulate antibody responses against leptospiral lipopolysaccharide, but do not provide cross-protective immunity against leptospiral serovars and generally produce only short-term immunity in domestic livestock (7, 8). So far, a large number of pathogenic and saprophytic serovars (>320) of Leptospira species have been described, which is a major limitation to the production of a multi-protein vaccine against multiple Leptospira serovars and development of immunization protocols based on whole cell or membrane preparations $(9,10)$. Moreover, due to lack of protection among carriage, hosts will shed the bacteria in their urine and contaminate the environments (11). Based on previous studies, several promising vaccine candidates are under evaluation. A human vaccine has been developed in China, but this vaccine is not protective in children under 14 years. A vaccine licensed for the human is still in experimental stage and therefore not approved for human usage $(7,12)$.

After whole genome sequencing of Leptospira species, a large number of leptospiral virulence factors, and surface proteins have been identified to represent new potential targets for the development of anti-leptospiral drug, vaccine and diagnostic strategies. Leptospira species express several outer surface proteins that may be promising candidates for the de- velopment of vaccines against leptospiral infections. LenA and LcpA proteins have been characterized as potential virulence factors. LcpA (leptospiral complement regulator-acquiring protein A) is a surface protein that binds both purified and soluble $\mathrm{C} 4 \mathrm{~b}$ binding protein (C4BP) from human sera (13). This protein is an outer membrane protein and contributes to pathogenic Leptospira immune evasion by binding to the complement system inhibitors (14). Based on previous studies, LcpA is found in serum resistance pathogenic Leptospira but not in non-pathogenic strains (15). LenA is a member of the leptospiral endostatin-like (Len) protein family, which interact with extracellular matrix (ECM), plasminogen (PLG), fibronectin, laminin, complement factor $\mathrm{H}$ and factor H-related protein-1 $(3,11)$. The genes coding for LcpA and LenA proteins are conserved among pathogenic strains of Leptospira (6).

To the best of our knowledge, no appropriate prophylactic studies on these leptospiral proteins have been reported. The effectiveness of these proteins in combination with LTB as an adjuvant remains to be evaluated. With the goal of discovering a new vaccine, the rLcpA, rLenA and rLTB recombinant proteins were produced in Escherichia coli BL21 (DE3) cells and their immunogenic potentials were considered in animal model.

\section{MATERIALS AND METHODS}

Cloning, expression and purification of recombinant proteins. Genomic DNAs of $L$. interrogans serovar Copenhageni strain Fiocruz L1-130 and ETEC (Enterotoxigenic Escherichia coli) ATCC 35401 were extracted using DNA extraction kit (Qiagen, Germany) according to the manufacturer's instructions. The extracted DNAs were stored at $-20^{\circ} \mathrm{C}$ until the proper time for the experiments. Amplification of $l c p A$, lenA and $l t b$ genes was carried out using specific forward and reverse primers, as shown in Table 1. Following enzyme digestion of gene amplicons and vectors carried out with restriction enzymes Xhol/HindIII (for lcpA gene), NdeI/XhoI (for LenA gene) and EcoRI/HindIII (for ltb gene) (Fermentas, Germany), respectively. The genes amplicons were cloned into pGH vector and then finally, len $A$ gene was subcloned into pET-15b, and $l c p A$ and $l t b$ genes sub-cloned into pET-28a expression vectors (Novagen, USA). The expression vectors were 
Table 1. List of primers used in study.

\begin{tabular}{llll}
\hline $\begin{array}{l}\text { Primer } \\
\text { name }\end{array}$ & Sequence (5' to 3') a & $\begin{array}{l}\text { Restriction } \\
\text { Enzyme }\end{array}$ & $\begin{array}{l}\text { Amplicon } \\
\text { size (bp) }\end{array}$ \\
\hline $\begin{array}{l}\text { LenA (F) } \\
\text { LenA (R) }\end{array}$ & GCCCCGGGCATATGATGAATTTAAAACAAGGAAATAAAA & SmaI, NdeI & 730 \\
LcpA (F) & GCCCCGGGCTCGAGCTGTTCTACACAGAGAAGATTTAG & SmaI, XhoI & \\
LcpA (R) & GCCCCGGGCTCGAGACAGCCAGGACCTTCG & SmaI, XhoI & 647 \\
LTB (F) & GCGATATCGAATTCGCTCCTCAGTCTATTACAGAACTA & SmaI, HindIII & \multirow{2}{*}{ EcoRV, EcoRI } \\
LTB (R) & GCGATATCCTCGAGGTTTTCCATACTGATTGCCGCAAT & EcoRV, HindIII & \\
\hline
\end{tabular}

${ }^{\mathrm{a}}$ Artificial restriction sites are underlined.

confirmed both by restriction enzyme digestion and sequencing.

The recombinant proteins were expressed in E. coli BL21 (DE3). Briefly, a single colony of transformed E. coli BL21 (DE3) containing pET-15b/lenA was cultured on $5 \mathrm{ml}$ Luria Bertani (LB) broth containing ampicillin $(100 \mu \mathrm{g} / \mathrm{mL})$ and incubated at $37^{\circ} \mathrm{C}$ overnight (about 16 h). Next day, $200 \mu \mathrm{l}$ of overnight culture was transferred into $5 \mathrm{ml}$ of LB broth containing ampicillin $(100 \mu \mathrm{g} / \mathrm{mL})$ at $37^{\circ} \mathrm{C}$ until the OD reached to 0.6 at $600 \mathrm{~nm}$. Then a final concentration of $1 \mathrm{mM}$ of IPTG (isopropyl- $\beta$-D-thiogalactopyranoside) [Sigma-Aldrich] was added to bacterial cultures and the cells were grown for 4 hours at $37^{\circ} \mathrm{C}$ with constant shaking. The control cultures without IPTG induction were used. The bacterial cultures were centrifuged at 5,000 rpm for 5 minutes. The pellet and supernatant were transferred to separate tubes, and the cell pellets were suspended in $100 \mu$ l sodium dodecyl sulfate-polyacrylamide gel electrophoresis (SDS-PAGE) sample loading buffer and were subjected to $12.5 \%$ SDS-PAGE.

For purification of the recombinant protein, transformed E. coli BL21 (DE3) overexpressed in $500 \mathrm{ml}$ Luria Bertani broth (Merck, Germany) containing ampicillin $(100 \mu \mathrm{g} / \mathrm{mL})$. The bacterial pellet was collected by centrifugation at $5000 \mathrm{rpm}$ for 5 minutes and the supernatant discarded. The precipitate was dissolved in $5 \mathrm{ml}$ lysis buffer $(8 \mathrm{M}$ urea, $100 \mathrm{mM}$ NaH2PO4, 10 mMTris-HCl, pH: 8.0) and following centrifugation at $12000 \mathrm{rpm}$ for 30 minutes. The supernatant loaded into Ni-NTA resin (Qiagen, Germany) column and shaken gently for 1 hour. The column was washed six times with washing buffers (urea 8 $\mathrm{M}, 6 \mathrm{M}, 4 \mathrm{M}, 2 \mathrm{M}, 1 \mathrm{M}$ and $0 \mathrm{M}$ with $\mathrm{pH}: 8.0$ ). The recombinant protein was then eluted using elution buf- fer (250 mM imidazole, $50 \mathrm{mM}$ NaH2PO $4.300 \mathrm{mM}$ $\mathrm{NaCl}, \mathrm{pH}: 8.0)$. Quality of protein purification was characterized by $12.5 \%$ SDS-PAGE method. The experiments similar to the described above, carried out for transformed E. coli BL21 (DE3) containing pET-28a/lcpA and pET-28a/ltb with kanamycin (50 $\mu \mathrm{g} / \mathrm{mL}$ ) as a selectable marker.

Western blotting. Western blotting carried out to establish protein expression using His-tag monoclonal antibody conjugated with horseradish peroxidase (HRP) (Thermo Fisher Scientific, Inc., Lithuania). The recombinant proteins were electrophoresed in $12.5 \%$ polyacrylamide SDS gel and transferred onto PVDF membrane (Bio-Rad, Hercules, CA, USA) for 90 min at $4{ }^{\circ} \mathrm{C}$. Membranes were blocked in PBS containing $3 \%$ skim milk and $0.05 \%$ Tween 20 at $4{ }^{\circ} \mathrm{C}$, overnight. After blocking, membranes were washed three times with PBS containing $0.05 \%$ Tween 20 and then incubated with His-tag monoclonal antibody conjugated with HRP (at 1:1000 dilution) for $1 \mathrm{~h}$ at $25^{\circ} \mathrm{C}$. Membranes were washed three times with PBS $1 \mathrm{X}$ containing $0.05 \%$ Tween 20 and then treated with 3, 3'-diaminobenzidine solution (Sigma-Aldrich, USA) for about $3 \mathrm{~min}$.

Vaccine formulation. Protein concentrations were determined using the method of Bradford. The vaccines were prepared in a proper proportion of recombinant proteins of rLenA and rLcpA with rLTB as an adjuvant. In control group, the hamsters immunized with rLTB alone. The solutions were mixed gently for $4 \mathrm{~h}$ at $4^{\circ} \mathrm{C}$ and stored at $4^{\circ} \mathrm{C}$ until use.

Hamster model of leptospirosis. Six groups consist of fifteen female Golden Syrian hamsters 
in each one, aged between 4 to 6 weeks, were used as the animal model. The vaccinated hamsters with the prepared protein compounds in this study, and a virulent isolate of L. interrogans serovar Copenhageni strain Fiocruz L1-130 were used to determine challenge dose, as described previously (16). The hamsters were immunized in the quadriceps muscle twice, with a 14-day interval between each immunization (days 0 and 14), as follows: rLenA-plus-LTB group, rLcpA-plus-LTB group, rLenA-plus-LcpAplus-LTB group and LTB group (control). Two additional groups, Bacterin and PBS, as positive and negative control groups, respectively, accompanied with four groups which mentioned above, were considered for challenge experiments. Thirty-four days after the first immunization, all of six groups of hamsters were challenged intraperitoneally with $10^{2}$ cells of the virulent isolate of Leptospira. Before first immunization and challenge, serum of the hamsters was collected from the retro-orbital venous plexus after administration of eye anesthetic drops, and the sera were stored at $-20^{\circ} \mathrm{C}$, until further analyses. The hamsters were checked every day for mortality over a period of 21 days. Survivors were sacrificed 21 days post challenge. All experiments were performed in accordance with animal handling protocols approved by the Institutional Animal Care and Use Committee.

Antibody response determination using ELISA. The ELISA assay was performed using a commercially available kit, 20 days after second immunization on sera from the vaccinated hamsters to determine the total antibody, $\operatorname{IgG}_{1}$ and $\mathrm{IgG}_{2}$ a isotypes. Briefly, the recombinant proteins $(10 \mu \mathrm{g} / \mathrm{mL})$ were adsorbed in PBS $1 \times$ buffer into 96-well polystyrene plates (Greinerbio-one, Fricken-hausen, Germany) overnight at $4^{\circ} \mathrm{C}$. ELISA plates were washed three times with PBST (PBS with $0.05 \%$ [v/v] Tween 20) and then blocked with PBS containing 4\% skim milk for $1 \mathrm{~h}$ at $25^{\circ} \mathrm{C}$. The plates were then washed three times using PBST, Hamster's sera were added into the wells at dilutions of 1:100 to 1:12800, and incubated for 1 $\mathrm{h}$ at $25^{\circ} \mathrm{C}$. Following rinses, Peroxidase-conjugated anti-golden Syrian hamster IgG antibody (Rockland) was added at a 1:6,000 dilution and incubated for one hour at room temperature. The plates were washed five times with PBST, o-phenylenediamine dihydrochloride (Sigma-Aldrich) substrate solution was added and the reaction was stopped with $4 \mathrm{~N} \mathrm{H} 2 \mathrm{SO} 4$.
Finally, optical density (OD) of mixtures was read at $492 \mathrm{~nm}$ by ELISA Reader.

Cytokine determination. The concentrations of IL-17, IL-4 and IFN $\gamma$ were measured by enzyme-linked immunosorbent assay. In brief, blood samples were collected from hamsters by eye bleeding after $16 \mathrm{~h}$ of the last immunization. Sera were separated from blood cells after coagulation at room temperature for $1 \mathrm{~h}$ and storage at $4^{\circ} \mathrm{C}$ for $1 \mathrm{~h}$ more with centrifugation at $12000 \mathrm{rpm}$ for $10 \mathrm{~min}$ at room temperature. The samples were analyzed for IL-4, IL-17 and IFN $\gamma$ using the sandwich ELISA assay according to the manufacturer's recommendations (eBioscience, San Diego, CA).

Statistical analysis. All of the Data were analyzed using SPSS software, version 22. Statistical Kruskal-Wallis test was used to compare the significant differences among different groups. The significant differences among groups were further analyzed by post hoc tests. The $p$ value $<0.05$ statistically was considered significant. All of the curves and charts in this study, were drawed up using GraphPad Prism 4 software.

\section{RESULTS}

Protein purification and western blotting analysis. After induction of the transformed E. coli BL21 (DE3) cells with IPTG as an inducer of gene expression, all of the recombinant proteins expressed as inclusion bodies. For purification, we used denaturing, re-naturing and eluting agents, respectively, and then yielded them as a soluble protein. The recombinant proteins were purified to near homogeneity by $\mathrm{Ni}$ NTA chromatography. All three purified recombinant proteins were observed based on predicted size on the migration of SDS-PAGE gels (approximately $30 \mathrm{kDa}$ for rLenA, $29 \mathrm{kDa}$ for $\mathrm{rLcpA}$, and $17 \mathrm{kDa}$ for rLTB). Also, these proteins reacted with the anti-His monoclonal antibody in Western blotting and appeared the intended bands (Figs. 1 and 2).

Immune response in vaccinated hamsters. Hyperimmune sera from the hamsters after the last booster injection were collected and titrated in all vaccinated groups by antigen-based ELISA. The highest OD in $492 \mathrm{~nm}$ (over 1:12800) of total IgG 


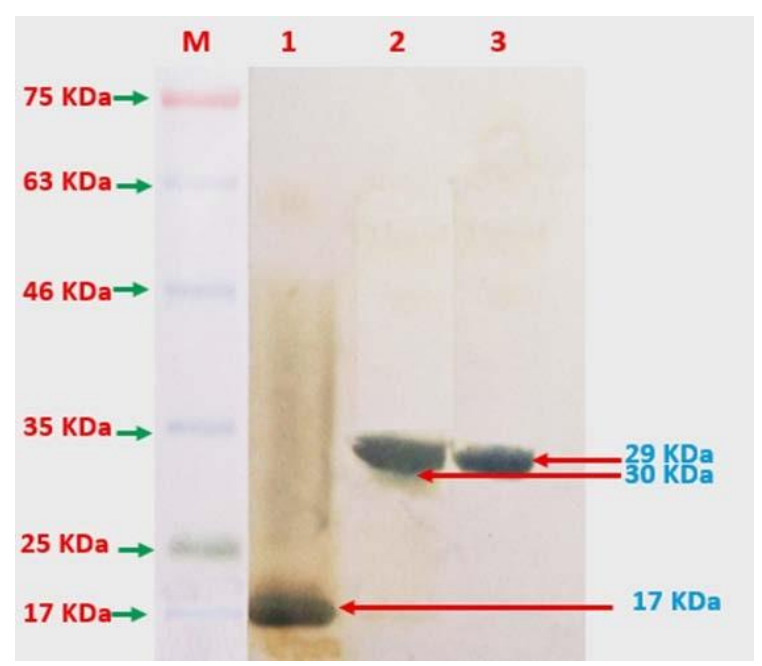

Fig. 1. Western blotting of purified rLTB (1), rLenA (2) and rLcpA (3) recombinant proteins. M: Protein size marker

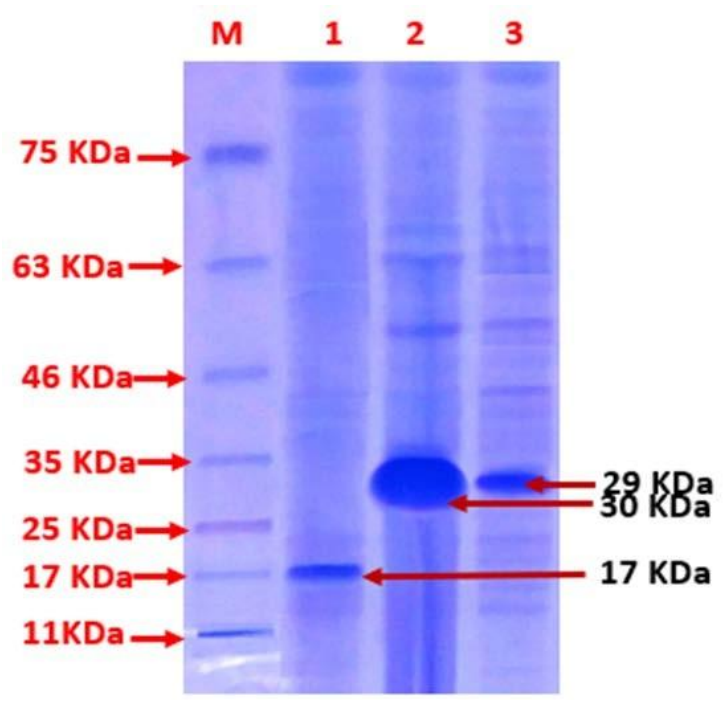

Fig. 2. Expression of rLenA, rLcpA and rLTB recombinant proteins in $12.5 \%$ gel M: Protein size marker, 1, 2 and 3 are rLTB, rLenA and rLcpA Proteins, respectively, after induction.

antibodies measured on the sera from the hamsters, was observed for rLenA-plus-rLcpA-plus-rLTB, rLenA-plus-rLTB, rLcpA-plus-rLTB, and rLTB groups, respectively. The rLenA-plus-rLcpA-plus-rLTB vaccine induced significantly higher antibody levels than the control group followed by rLenA-plus-rLTB $(p<0.05)$. RLcpA-plus-rLTB and rLTB proteins did not induce any significant antibody response in vaccinated hamsters $(p>0.05)$ (Fig. 3). The types of im- mune responses to the recombinant proteins were further examined by measuring the levels of $\operatorname{IgG}$ and $\mathrm{IgG}_{2}$ a subclasses. The hamsters inoculated with recombinant proteins had significantly higher $\operatorname{IgG}$ titers than $\mathrm{IgG}_{2}$ a in comparison to control groups with a statistical significance $(p<0.05)$ (Fig. 4).

Efficacy of vaccine preparations. The protective efficacy of the rLenA and rLcpA in combination with rLTB vaccine preparations were evaluated. The hamsters which were immunized with the mentioned protein compositions and also Bacterin and PBS (control) groups, were challenged with $10^{2}$ cells of L. interrogans serovar Copenhageni strain Fiocruz L1-130, intraperitoneally injection. The hamsters immunized with the rLenA-plus-rLcpA-plus-rLTB, rLenA-plus-rLTB and rLcpA-plus-rLTB, showed statistically significant improvement $(p<0.05)$ in survival rate after bacterial challenge (Fig. 5). The median survival times for hamsters immunized with the recombinant proteins were significantly longer than hamsters received PBS alone $(p<0.05)$. The highest survival rate was observed in rLenA-plus-rLcpAplus-rLTB group.

Cytokine expression profile in immunized hamsters. A significant amount of IL-17, IL-4 and IFN $\gamma$ cytokines was produced in immunized hamsters (Fig. 6). There were not statistically significant differences $(p>0.05)$ between the groups. The levels of IFN $\gamma$ in the immunized hamsters with rLenAplus-rLcpA-plus-rLTB, rLenA-plus- rLTB and rLcpA-plus-rLTB did not show statistically significant difference $(p>0.05)$ with group received rLTB alone.

\section{DISCUSSION}

Leptospira has a wide variety of mechanisms that enable it to evade the host immune system and enhance the severity of the infection. The identification of protective antigens is needed to facilitate vaccine-based prophylactic approaches. Some of identified proteins contribute to the ability of the bacteria to adhere, invade and colonize onto the host tissues. Towards controlling the increasing problem of leptospirosis, for the first time we evaluated, LenA and LcpA proteins from L. interrogans serovar Copenhageni strain Fiocruz L1-130 in combination with E. coli heat-labile enterotoxin, B subunit (LTB) as 


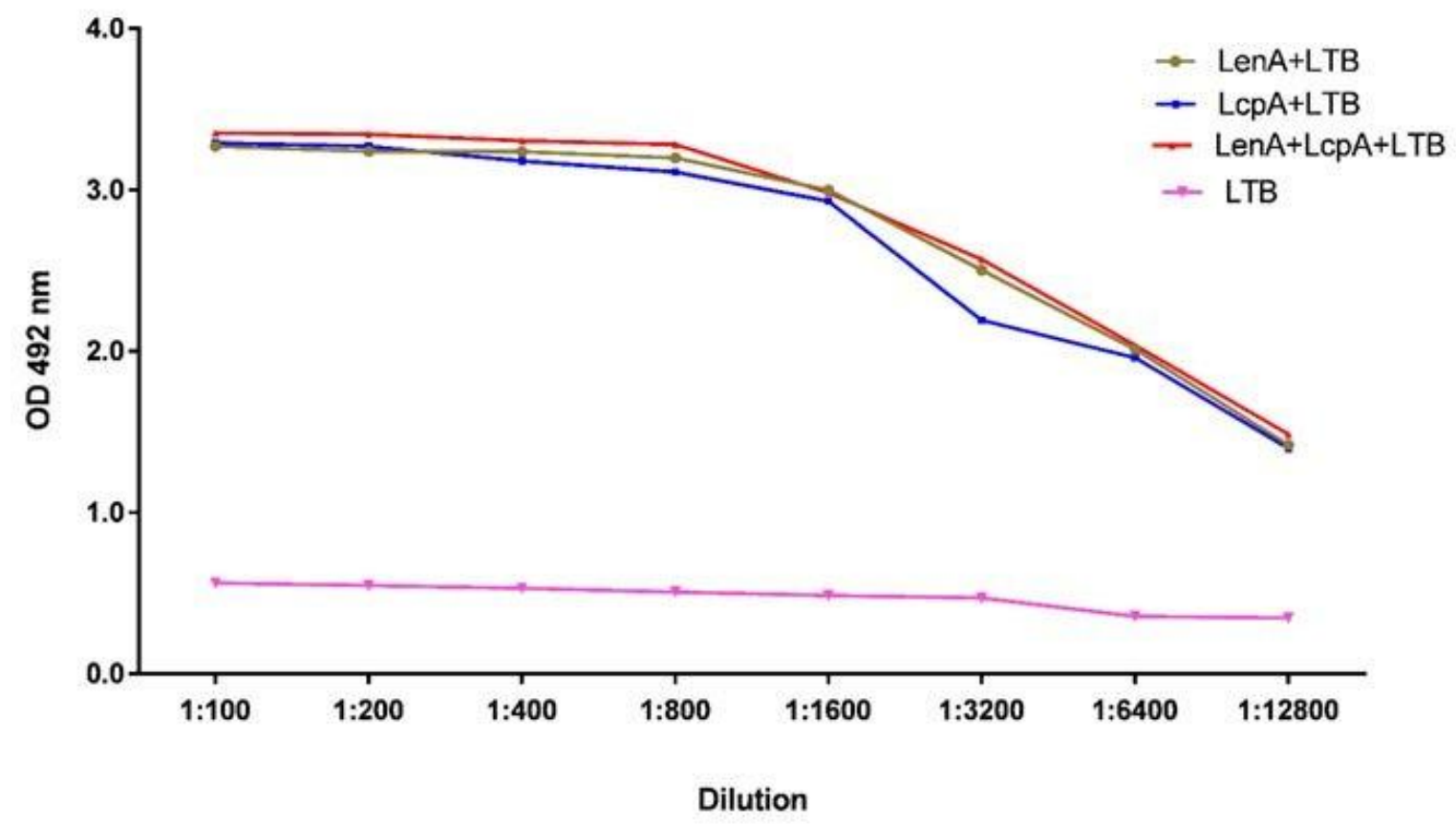

Fig. 3. Titration of Total IgG antibodies in sera of immunized hamsters. Twenty days after the last immunization serum samples of the animals were collected and pooled. The sera were serially diluted and were coated on recombinant proteins. Different groups of animal seach consisting of 15 hamsters were administrated with either the rLenA, rLcpA and rLTB recombinant proteins. The titers of Total IgG antibodies were significantly high in hamsters $(\mathrm{p}<0.05)$.
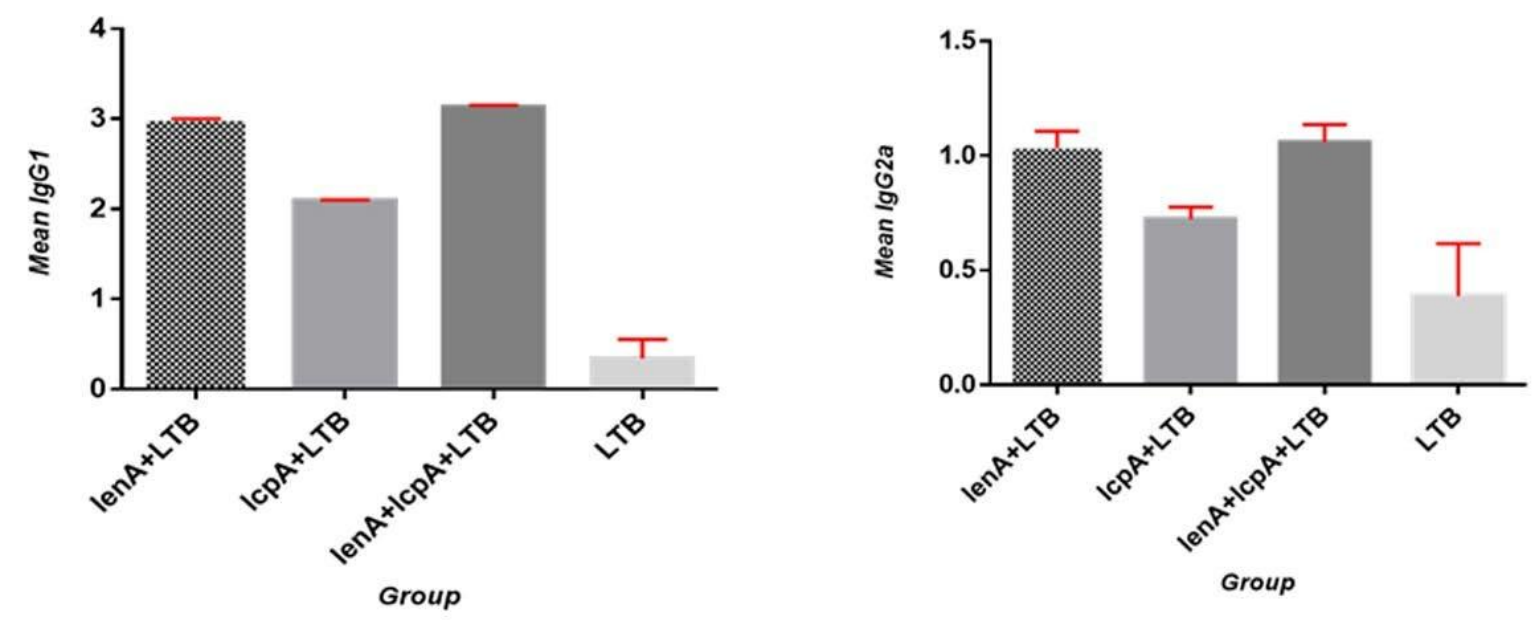

Fig. 4. Immunoglobulin isotyping assay in sera of immunized hamsters. Twenty days after the last immunization serum samples of the animals were collected and pooled. The sera were serially diluted and were coated on recombinant proteins. Different groups of animals each consisting of 15 hamsters were administrated with either the rLenA, rLcpA and rLTB recombinant proteins. The $\mathrm{IgG}_{1}$ levels were higher than $\mathrm{IgG}_{2}$ a levels in comparison to control group (LTB). The $\operatorname{IgG}_{1}$ and $\operatorname{IgG}_{2}$ a levels against rLcpA were lower than other proteins. 


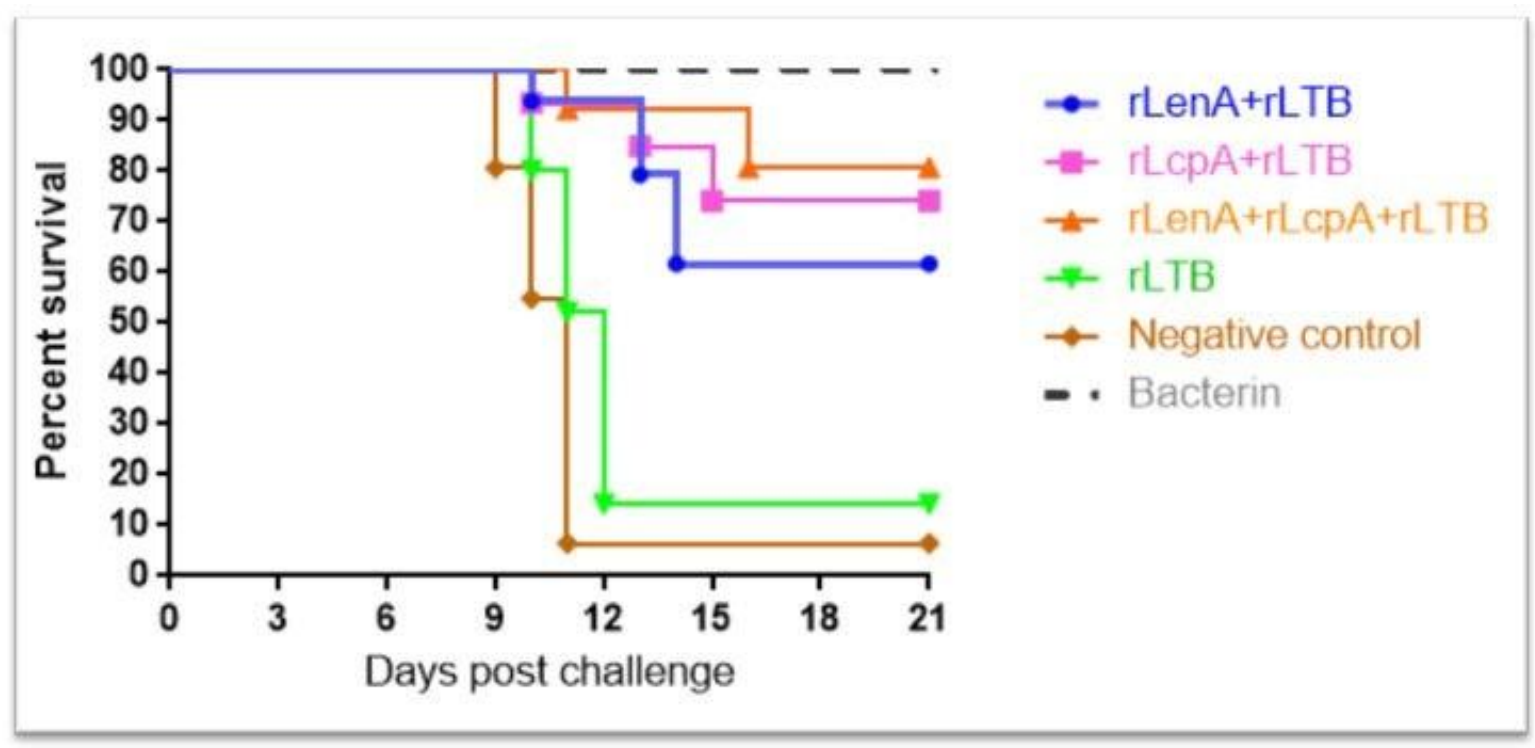

Fig. 5. Cumulative survival rates of hamsters challenged with $L$. interrogans serovar Copenhageni strain Fiocruz L1-130. The hamsters were intraperitoneally infected with $10^{2}$ cells of $L$. interrogans. The Survival rates of each group were checked for 21 days. There were statistically significant differences $(p<0.05)$ between immunized hamsters and control groups.
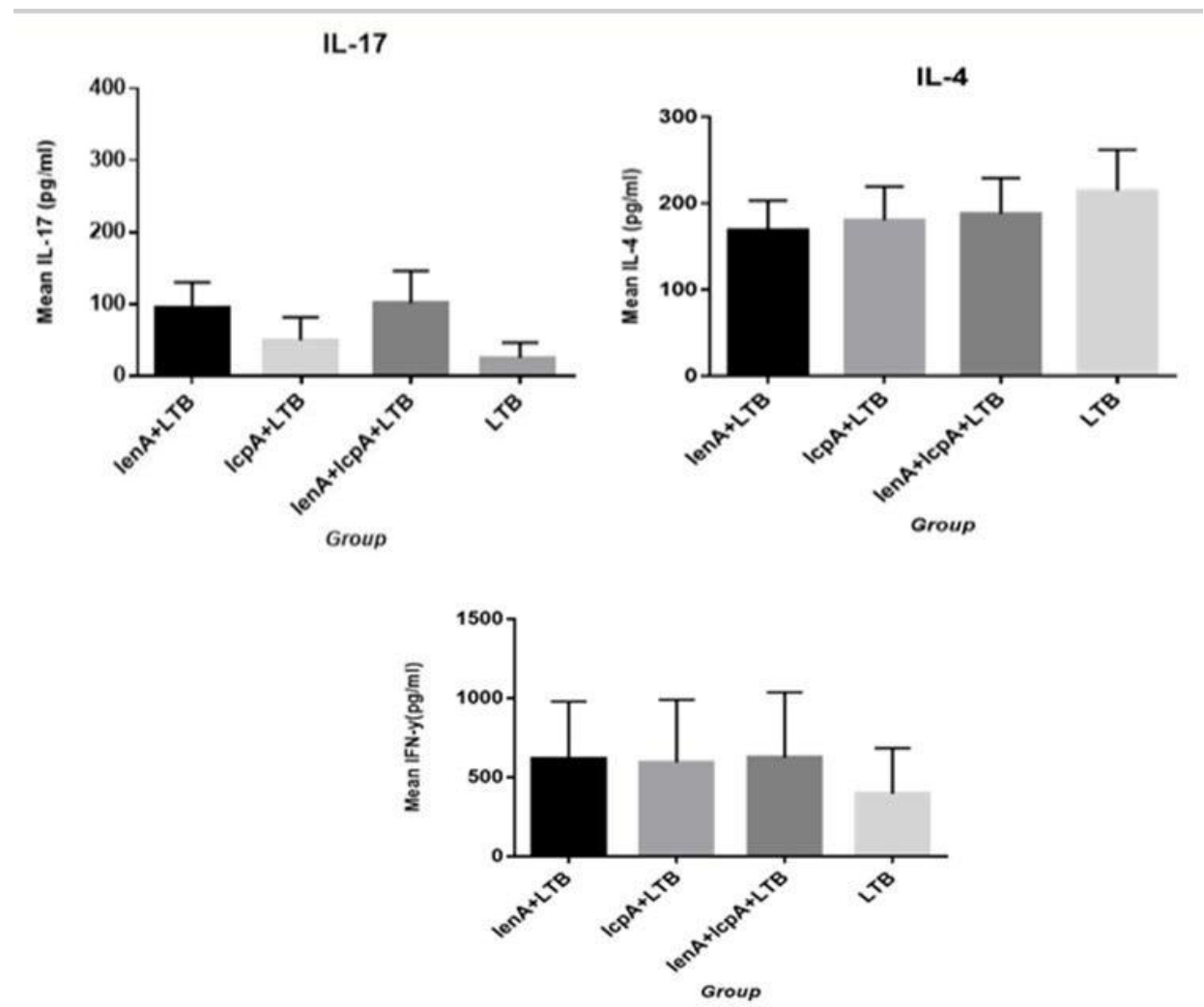

Fig. 6. Levels of IL-4, IL-17 and IFN $\gamma$ cytokines (pg/mL) in hamsters. The levels of IL-17 was very low compared to two other cytokines and did not show statistical differences with group that received rLTB alone $(p>0.05)$. There were no statistically significant differences $(p>0.05)$ between the groups. 
potential candidates for vaccine production against Leptospiral infections.

The available leptospiral vaccines are based on inactivated whole-cell or membrane preparation (18). However, these vaccines stimulate antibody responses, fail to induce immune memory and consequently require booster injections. Moreover, these vaccines bear considerable side-effects and do not provide cross-protective immunity against serovars $(19,20)$. Leptospiral immunoglobulin-like (Lig) proteins are probably the best vaccine candidates, as they demonstrated $90-100 \%$ of protection in immunized hamsters that survived lethal bacterial challenge. However, these proteins are not conserved amongst all pathogenic strains and sterilizing immunity has not yet been achieved $(21,22)$, highlighting the need for new conserved antigens for development of a better vaccine. In the present study we evaluated two protein LenA and LcpA which are highly conserved among all pathogenic leptospires and could potentially confer cross-protection. However, these proteins showed lower protection $(60-80 \%)$ in comparison to Lig proteins.

Our results showed that the rLenA and rLcpA proteins in combination with rLTB induce high IgG titers in hamsters. Similar studies demonstrated that cell surface protein Lig could produce high IgG titers in hamsters (18). In another similar study conducted by Oliveira et al., recombinant OmpL 37 induced a strong $\mathrm{IgG}$ response in hamsters inoculated with different vaccine formulations (21). In this study, recombinant proteins were emulsified with rLTB as adjuvant, which generated high titers of anti-LcpA and anti-LenA. A comparable study that used LTB along with recombinant protein LipL 32 showed significantly high titers against the leptospiral antigen (23).

In this study, the plasma level of IFN gamma produced in the hamsters immunized by rLenA and rLcpA recombinant proteins was higher than IL-4 and IL-17. The high-level production of this cytokine in response to recombinant proteins may be due to the stimulation of Th-1 lymphocytes. Potent vaccine protection against leptospirosis has attributed to induction of Th-1 immune responses $(23,24)$. Several studies have reported that Th-1 and other components of innate immune systems are essential for bacterial clearance in animal models $(24,25)$.

Results of present study revealed that the rLenA and rLcpA recombinant proteins efficiently stimulated cell mediated immunity. Our results predict that these proteins in combination with LTB recombinant have the potential for broad protective coverage against leptospiral infection. Both rLenA and rLcpA proteins can be used as candidate for vaccine development along with rLTB for better efficacy. Further investigation on the role of rLenA and rLcpAin ligand binding and epitope mapping delineation might be necessary to further improvement of the leptospiral vaccines. Studies tailored towards identifying novel potential vaccine candidates against leptospiral infections are essential and still need.

\section{ACKNOWLEDGEMENTS}

Tehran University of Medical Science TUMS has financially supported this study as part of $\mathrm{PhD}$ thesis and is recognized by the research grant Ref. No: 31382. The study protocol was reviewed and with code of ethics No: IR.TUMS.SPH.REC.1395.1839 approved by the ethical review committee of Tehran University of Medical Sciences for animal studies.

We thank all the staffs of the Pathobiology Department at TUMS for their technical and intellectual assistance.

\section{REFERENCES}

1. Faraji H, Mirzaei H, Afshar D, Nouri P, Roshanjo K, Mohamadi Bardebari A, et al. The epidemiology of Leptospira infection in Mazandaran province, northern Iran, during 2012 - 2013. Iran Red Crescent Med J 2016;18(7): e23194.

2. Vijayachari P, Sugunan AP, Shriram AN. Leptospirosis: an emerging global public health problem. J Biosci 2008;33:557-569.

3. Domingos RF, Vieira ML, Romero EC, Gonçales AP, de Morais ZM, Vasconcellos SA, et al. Features of two proteins of Leptospira interrogans with potential role in host-pathogen interactions. BMC Microbiol 2012; 12:50.

4. Barbosa AS, Monaris D, Silva LB, Morais ZM, Vasconcellos SA, Cianciarullo AM, et al. Functional characterization of LcpA, a surface-exposed protein of Leptospira spp. that binds the human complement regulator C4BP. Infect Immun 2010; 78:3207-3216.

5. Domingos RF, Fernandes LG, Romero EC, de Morais ZM, Vasconcellos SA, Nascimento AL. Novel Leptospira interrogans protein Lsa32 is expressed during infection and binds laminin and plasminogen. Micro- 
biology 2015; 161:851-864.

6. Raja V, Natarajaseenivasan K. Pathogenic, diagnostic and vaccine potential of leptospiral outer membrane proteins (OMPs). Crit Rev Microbiol 2015; 41:1-17.

7. Gamberini M, Gómez RM, Atzingen MV, Martins EA, Vasconcellos SA, Romero EC, et al. Whole-genome analysis of Leptospira interrogans to identify potential vaccine candidates against leptospirosis. FEMS Microbiol Lett 2005; 244:305-313.

8. Palaniappan RU, Chang YF, Jusuf SS, Artiushin S, Timoney JF, McDonough SP, et al. Cloning and molecular characterization of an immunogenic LigA protein of Leptospira interrogans. Infect Immun 2002; 70:5924-5930.

9. Breda LC, Hsieh CL, Castiblanco Valencia MM, da Silva LB, Barbosa AS, Blom AM, et al. Fine Mapping of the Interaction between $\mathrm{C} 4 \mathrm{~b}$-Binding Protein and Outer Membrane Proteins LigA and LigB of Pathogenic Leptospira interrogans. PLoS Negl Trop Dis 2015; 9(10):e0004192.

10. Zarantonelli L, Suanes A, Meny P, Buroni F, Nieves $\mathrm{C}$, Salaberry X, et al. Isolation of pathogenic Leptospira strains from naturally infected cattle in Uruguay reveals high serovar diversity, and uncovers a relevant risk for human leptospirosis. PLoS Negl Trop Dis 2018; 12(9):e0006694.

11. Robbins GT, Hahn BL, Evangelista KV, Padmore L, Aranda PS, Coburn J. Evaluation of cell binding activities of Leptospira ECM adhesins. PLoS Negl Trop Dis 2015; 9(4):e0003712.

12. Faine S, Adler B, Bolin C, Perolat P. (1999) Leptospira and Leptospirosis, 2nd edn. MediSci, Melbourne, Australia.

13. Choy HA. Multiple activities of LigB potentiate virulence of Leptospira interrogans: inhibition of alternative and classical pathways of complement. PLoS One 2012; 7(7):e41566.

14. Barbosa AS, Monaris D, Silva LB, Morais ZM, Vasconcellos SA, Cianciarullo AM, et al. Functional characterization of LcpA, a surface-exposed protein of Leptospira spp. that binds the human complement regulator C4BP. Infect Immun 2010; 78:3207-3216.

15. da Silva LB, Miragaia Ldos S, Breda LC, Abe CM, Schmidt MC, Moro AM, et al. Pathogenic Leptospira species acquire factor $\mathrm{H}$ and vitronectin via the surface protein LcpA. Infect Immun 2015; 83:888-897.

16. Silva EF, Medeiros MA, McBride AJ, Matsunaga J,
Esteves GS, Ramos JG, et al. The terminal portion of leptospiral immunoglobulin-like protein LigA confers protective immunity against lethal infection in the hamster model of leptospirosis. Vaccine 2007; 25:62776286.

17. Gonçalves-de-Albuquerque CF, Burth $\mathrm{P}$, Silva AR, Younes-Ibrahim M, Castro-Faria-Neto HC, Castro-Faria MV. Leptospira and inflammation. Mediators Inflamm 2012; 2012:317950.

18. Dellagostin OA, Grassmann AA, Rizzi C, Schuch RA, Jorge S, Oliveira TL, et al. Reverse vaccinology: an approach for identifying Leptospiral vaccine candidates. Int J Mol Sci 2017; 18:E158.

19. Teixeira AF, Fernandes LGV, Souza Filho A, Souza GO, Vasconcellos SA, Heinemann MB, et al. Evaluation of Lsa46 and Lsa77 Leptospiral proteins for their immunoprotective activities in hamster model of Leptospirosis. Biomed Res Int 2018; 2018:1813745.

20. Grassmann AA, Kremer FS, Dos Santos JC, Souza JD, Pinto LDS, McBride AJA. Discovery of novel Leptospirosis vaccine candidates using reverse and structural vaccinology. Front Immunol 2017; 8:463.

21. Oliveira TL, Grassmann AA, Schuch RA, Seixas Neto AC, Mendonça M, Hartwig DD, et al. Evaluation of the Leptospira interrogans Outer membrane protein OmpL37 as a vaccine candidate. PLoS One 2015; 10(11):e0142821.

22. Conrad NL, Cruz McBride FW, Souza JD, Silveira MM, Félix S, Mendonça KS, et al. LigB subunit vaccine confers sterile immunity against challenge in the hamster model of leptospirosis. PLoS Negl Trop Dis 2017; 11(3):e0005441.

23. Grassmann AA, Félix SR, dos Santos CX, Amaral MG, Seixas Neto AC, Fagundes MQ, et al. Protection against lethal leptospirosis after vaccination with LipL32 coupled or coadministered with the B subunit of Escherichia coli heat-labile enterotoxin. Clin Vaccine Immunol 2012; 19:740-745.

24. Lin X, Xiao G, Luo D, Kong L, Chen X, Sun D, et al. Chimeric epitope vaccine against Leptospira interrogans infection and induced specific immunity in guinea pigs. BMC Microbiol 2016; 16:241.

25. Zuerner RL, Alt DP, Palmer MV, Thacker TC, Olsen SC. A Leptospira borgpetersenii serovar Hardjo vaccine induces a Th1 response, activates NK cells, and reduces renal colonization. Clin Vaccine Immunol 2011; 18:684-691. 